Sir,

\section{Re: Changing prevalence of respiratory symptoms and treatment in Dutch school children: 1989 - 1997}

The serial surveys of prevalence of respiratory symptoms suggestive of asthma in Dutch schoolchildren reported by Mommers et al. (Prim Care Resp J 2002;11:38-41) makes a valuable contribution to our understanding of the epidemiology of respiratory symptoms in childhood. Key strengths of this study were, in my opinion, the use of the same validated screening instrument in each survey and the excellent response rates obtained.

It is in the presentation and interpretation of results however that I feel further clarification is needed. Firstly, as the authors' acknowledge, 22 separate tests of significance were performed raising the possibility of Type 1 errors arising from multiple testing. One standard approach to adjusting for multiple tests of significance is the use of a Bonferroni correction and the authors should be encouraged to use this approach to assess whether the changes in symptom prevalence reported remain significant. ${ }^{1}$

A second point, and one that may need to be incorporated into the Journal's policy is the need for authors to be encouraged to report actual p-values, even when not significant at the 0.05 level. Simply stating 'NS' to denote not significant is I believe unhelpful as important trends may be masked. ${ }^{2-3}$ An example of this in the present paper is that in the abstract it is reported that the prevalence of 'shortness of breath increased from $7.4 \%$ to $9.6 \%(\mathrm{p}=0.056)$ ' whereas in Table 2 the same result is reported as $\mathrm{p}=\mathrm{NS}$.

\section{Dr Aziz Sheikh}

Prim Care Resp J 2002: 11(4);132

NHS/PPP National Primary Care Post Doctoral Fellow Department of Public Health Sciences, St George's Hospital Medical School, Cranmer Terrace, London SW17 0RE

\section{References}

1.Altman DG. Practical statistics for medical research. London: Chapman \& Hall, 1991: 211.

2.Sheikh A, Cook AD. Statistical notes III: Hypothesis testing.

Primary Care Respiratory Journal 2000:9:16-17.

3.Cook AD, Sheikh A. Statistical notes IV: Estimation understanding confidence intervals. Primary Care Respiratory Journal 2000;9:48-50.

Sir,

In his comment on our publication (Prim Care Resp J 2002;11:3841) Dr Sheik recommends the use of the Bonferroni correction method. The Bonferroni correction has been reported to be highly conservative for large number of comparisons, but its use is reasonable for small number of comparisons (up to five). ${ }^{1}$ We therefore chose not to use this correction method but to comment on the issue of Type I error instead.

The second point made, is the reporting of actual p-values. We fully agree that using the actual $\mathrm{p}$-values is more informative than only stating 'NS' to indicate non-significance. To clarify the p-values, the Editor added 'NS' etc. to the actual p-values as we reported them in our publication. The electronic version included both the actual $\mathrm{p}$-values and the description 'NS'. We regret that in the printed version, as we later learned, the actual p-values had been omitted.

\author{
Monique Mommers, Ron Derkx, Gerard Swaen \\ Onno van Schayck \\ Prim Care Resp J 2002: 11(4);132
}

Researchinstitute for Extramural and Transmural Health Care University of Maastricht, P.O. Box 616 6200 MD Maastricht, The Netherlands

\section{References}

1. Altman DG. Practical statistics for medical research. London: Chapman \& Hall, 1991:211.

Sir,

\section{Pesticides and respiratory disorders in rural areas}

Respiratory disease is an important clinical problem for agricultural workers. Numerous studies have demonstrated a significantly increased risk of respiratory morbidity and mortality among farmers. In developed countries such as the United States, less than $5 \%$ of the economically active population is involved in agriculture 1 . In Greece this percentage rises to about $50 \%$. While agriculture may be a single industry, it is extremely diverse with substantial respiratory hazards occurring from organic and inorganic dusts, chemicals and gases. Recently we showed that about all farmers or part time farmers who lived in a rural area of Greece used pesticides. In about one out of ten Greek rural families, their adolescents used also pepticides. The prevalence of respiratory diseases in there groups of subjects were more than expected. Pesticides encompasse several subcategories from herbicides to insecticides, fungicides, nematicides, acapcides and biocides 2 . For the vast majority of reported cases, the dermal route exceeds inhalation in overall occupational pesticide exposure, but respiratory exposure assumes great importance. Noxious gases and irritants may directly injure the airway epithelia resulting in edema, inflammation and cell death. Chronic airflow limitation results from both airway obstuction and loss of elastic recoil in the parenchyma. In contrary to previous studies, Greek farmers smoke more than other people in most occupations3.

Our data showed that in rural area in Greece and may be in other countries, there are many farmers part-time farmers, including their children, who are full-time smokers with many respiratory problems. Primary health care services which are generally less available in rural areas should take care of the farmers' exposure in noxious gases. Agricultural respiratory diseases must be considered in the context of both agricultural health care delivery and the characteristics of the particular population.

\section{KI Gourgoulianis ${ }^{1}$ PA Molyvdas ${ }^{2}$ \\ Prim Care Resp J 2002: 11(4);132}

(1) Pulmonary depatment, Medical School, University of Thessaly, Greece (2) Physiology depatment, Medical School, University of Thessaly, Greece

\section{References}

1.Jeyaratnam J. Occupational health issues in developing countries. Environ Res 1993;60:207-212.

2.Mehler LN, O' Malley MA Krieges KI. Acute pesticide morbidity and mortality: California Rev Environ Contam Toxicol 1992;

129:518-566.

3.Gillum RF. Prevance of cardiovascular and pulmonary diseases and risk factors by region and urbanization in the United States. $J$ Natl Med Assoc 1994; 86:105-112. 